\title{
FAMILY COUNSELING TECHNIQUES
}

\section{LEARNING OBJECTIVES}

Just as individuals are profoundly impacted by substance use disorders (SUDs), so too are their families, friends, coworkers, and significant others. In this chapter, we will explore how couples and families are impacted by SUDs and will present a variety of treatment models and techniques that are specific to treating couples and families. We will also explore how enabling and codependent behaviors evolve, often as survival roles. By the end of this chapter, you will be able to:

- describe healthy family traits and how SUDs can erode healthy family functioning;

- identify family roles (both spouse-partner and child roles) that are common in SUD families;

- explain how and why SUDs can impact families as well as family progression;

- describe family treatment models (e.g., Family Systems, Structural and Behavioral models) and the treatment techniques that coincide with these models;

- describe the three family treatment entry points;

- describe how families can motivate loved ones who are actively using substances;

- describe family treatment models specific to treating SUDs in adolescents;

- describe the special treatment needs of adult children of alcoholics.

\section{TERMS TO KNOW}

alliances

boundaries unspoken agreements between family members to support one another especially during times of family conflict. Alliances can be supportive and healthy or dysfunctional, e.g., "I'll protect your drinking if you protect mine"

boundaries are usually physical as well as psychological barriers that exist both within families and with the outside world. Each individual family member may have their own physical or emotional boundary or comfort zone 


\section{circular \\ causality}

collusion

differentiation

enabling

emotional

cutoffs

enmeshment

family of origin

family of

creation

family roles

identified

patient (IP) often problems within families do not occur in a linear fashion (e.g., behavior A causes reaction B) but rather in viscous cycles that tend to be self-perpetuating and often self-defeating. If a couple's arguing results in one partner leaving to drink or use drugs, followed by promises to change that are not forthcoming, which results in more arguing, this exemplifies circular causality

similar to alliances, collusion implies that two family members are colluding or allying together against other family members the ability of a son or daughter to separate from one's family of origin and form new healthy adult relationships

when family members inadvertently support their loved one's drinking or drug use by providing them with comforts (e.g., money, food, and shelter) or by providing excuses to others for their loved one's aberrant behavior. For example, a husband might enable his wife's drinking by calling her boss to say "she's sick" when in fact she is hungover from drinking the night before

when a family member refuses to communicate with or have contact with another family member or someone outside the family

when family members are overinvolved with one another to the point where healthy differentiation is nearly impossible to achieve. Enmeshed relationships usually lack appropriate boundaries. Enmeshment is similar to "fusion"

the family that someone grows up in, usually with biological or adoptive parents or guardians (e.g., grandparents) and sometimes siblings

this is a family often composed of friends and parental figures who care for one another. There is often a give-and-take relationship among this group of individuals. A family of creation may include members of one's family of origin as well as individuals who are completely unrelated and perhaps unknown to one another

it is common for family members in homes impacted by SUDs to take on certain roles. Spouses or partners may take on the role of the enabler or the placater, while children may take on the role of the hero or scapegoat

when families seek treatment, there is usually a person who becomes the symptom-bearer or IP within the family. This may or may not be the individual who is experiencing a SUD, but may be a family member who is experiencing behavioral or emotional adjustment problems 
negative

feedback loop

triangulation circular communication pattern that represents a no-win outcome. For example, a spouse telling their wife, "I drink because you nag me all the time." While the wife may respond with, "If you didn't drink so so much, I wouldn't nag you"

when an unstable dyad (like a husband and wife or life partners), as a result of experiencing conflict or instability in their relationship, draw in a third party (e.g., a son or daughter or other family member) who then becomes the target of their conflict

\section{INTRODUCTION}

Substance use disorders (SUDs) do not occur in a vacuum, and it is often estimated that for every one individual impacted by a SUD there are, on average, six others who are also affected. This includes family members, spouse/partners, friends, coworkers, and other acquaintances. In this chapter, we will explore the impact of SUDs on families and significant others. Keep in mind that, although it may be common for a client impacted by SUDs to claim that a nagging, demanding spouse or partner or their "pain-in-the-neck kids" drove them to drink (or use drugs), this is more than likely not the case. Many people live in stressful job or family circumstances, but not all cope by relying on mood-altering substances. Yet, what is certain is that years of alcohol and/or substance abuse puts incredible stress and strain on most families and couples' relationships.

Families that are impacted by SUDs tend to share many similarities in terms of how their suffering and dysfunction play out on a day-to-day basis. It is also important to consider when discussing families experiencing SUDs that we are not only referring to families where a parent exhibits an alcohol use disorder (AUD) or SUD but also families where a grandparent or an adolescent/young adult son or daughter is experiencing a SUD. In addition, there are also instances where one or both partners in a couple's relationship is experiencing alcohol and/or drug issues. Therefore, there are a variety of situations where individuals are impacted by SUDs and so are their significant others.

To begin the exploration of families impacted by SUDs, it is important to examine what healthy families look like in order to understand how alcohol or substance abuse erode the very qualities or characteristics that allow families to function in a healthy way. As the famous author Tolstoy remarked in Anna Karenina, "All happy families are alike, each unhappy family is unhappy in its own way." So, let us examine some of the traits that characterize healthy families:

1. Healthy family members trust one another.

2. Healthy family members are able to communicate with one another in a clear and direct manner and are able to express loving feelings toward one another.

3. Healthy families value and validate each other's feelings.

4. Healthy family members are invested in the emotional growth of each individual within that particular family.

5. Healthy family members value interdependence (i.e., they can count on one another). 
6. Healthy families value independence and autonomy.

7. Healthy families have appropriate rules and boundaries.

8. Healthy families are invested in teaching younger family members.

9. Healthy families value and enjoy leisure time together.

10. Healthy families celebrate holidays, anniversaries, and birthdays via special rituals.

11. Healthy families value connection with extended family members (e.g., grandparents, aunts, uncles, and cousins; adapted from Walsh, 1993).

As mentioned earlier, all of the qualities that allow families to function in healthy ways can be affected and eroded when a family member is actively abusing alcohol or other substances. For example, in healthy families, communication is often

\section{LEARNING ACTIVITY 8.1 HEALTHY FAMILY TRAITS}

Review the list of healthy family traits and choose the ones that you feel are applicable to your family. Are there traits on the list that you wish were present in your family? clear and direct, whereas in families impacted by SUDs communication suffers and becomes indirect, vague, confusing, or contradictory. Take the following scenario as an example.

\section{CASE EXAMPLE: JENNA}

Jenna is 19 years old and was a sophomore in college and living on campus until being placed on a "disciplinary leave" because of an incident in which she assaulted a fellow student while under the influence. Jenna was so intoxicated when the assault occurred that she was taken to a local ED and had her stomach pumped (her blood alcohol level [BAL] was determined to be .28). Jenna is now back home living with her parents and younger sister, Cara. Jenna's parents are furious that she was asked to leave the university. They had concerns about Jenna's drinking from the time she was in high school; however, they felt she would eventually grow out of her risky behavior. Jenna's parents want her to go to counseling (which is a stipulation of her being readmitted to classes in the fall); however, Jenna states she is thinking of applying to another university anyway "so why bother?" There is constant arguing and tension in the home, and Jenna responds by shutting down any meaningful communication and storming out to go out partying with her friends. Jenna's mother feels that her husband needs to take a more active role in disciplining Jenna by making her get a job and forcing her to go to counseling. Jenna's father is angry both at Jenna and his wife for forcing him to become "the disciplinarian." Whenever Jenna needs money to go out with her friends, she will nag her father because Jenna knows she can usually get him to give in. This makes Jenna's mother even more infuriated at both of them. Jenna states that her mother's "constant nagging" only makes her want to go out more with her friends to "party" to escape all the tension at home. Also, in response to all the tension and family disorder, Jenna's younger sister, Cara, has developed panic attacks. 


\section{LEARNING ACTIVITY 8.2 JENNA}

Before you read the case conceptualization of Jenna's family, see if you can identify some of the dynamics that characterize Jenna's family (e.g., what are the patterns of communication between family members? What are the power struggles within the family?). Also, see if you can identify any alliances or evidence of collusion. Who is the enabler and how does this person enable? Can you find evidence of a negative feedback loop (as described in the Terms to Know)? Who are the "symptom bearers," and if this family were to present for counseling, who would most likely be the identified patient (IP)? Finally, if you were asked to see Jenna and her family, what would be the most important issues to address?

\section{Case Conceptualization: Jenna}

Jenna's family is a good illustration of the type of conflictual communication that occurs in the families where SUDs are present. Problems rarely get talked out or resolved. Instead, Jenna has become quite skilled in being able to pit her parents against one another for her own benefit. Jenna is also resistant to her university discipline committee's recommendation that she seek counseling, even if it means that she will end up transferring to another university. Her mother recognizes that Jenna needs to address her drinking and is therefore reluctant to give Jenna a way of avoiding treatment. This case also provides an example of triangulation, as Jenna has been able to pit her parents against one another. The other possibility is that the instability in the parents' relationship is being played out with Jenna taking on the role of the scapegoat in order to take the focus off of the parents' unstable marital relationship. For example, there are dysfunctional communication patterns between the parents, as Jenna's mother feels that Jenna needs to face the consequences of her behavior, while her father seems to be enabling Jenna's attempts to escape these consequences. Also, while Jenna continues to party with her friends who did not go away to college, she claims she does so because her mother nags her "all the time," while her mother feels that she needs to nag Jenna because she drinks most nights and then does nothing during the day. This is an example of a negative feedback loop and circular causality. Jenna's younger sister, Cara also has become a symptom-bearer as she too has developed difficulties in coping within familial stress by developing panic attacks. Life for Jenna and her family has become a far cry from the healthy family traits mentioned earlier. Instead, the dynamics occurring in Jenna's family represent very much the opposite of "healthy family traits." Not surprisingly, research indicates that healthy family traits and dynamics often serve as a protective factor against sons and daughters developing SUDs (Leonard \& Homish, 2008).

With regard to communication patterns in families impacted by SUDs, it is often said that there are three "unwritten rules" of living in a home impacted by alcohol or drug addiction, "Don't trust, Don't talk, and Don't feel" (Black, 1981). These rules often apply to homes wherein sons or daughters live at home with a parent(s) with active SUDs. Children of alcoholic or addicted parents often learn not to trust anyone with family secrets surrounding Mom or Dad's alcohol or drug problem and to refrain from talking about anything that goes on at home, behind closed doors. In order to survive in such a dysfunctional system, sons or daughters also learn to suppress or stuff their feelings (Don't feel). When feelings are expressed, they usually tend to be invalidated, dismissed, or used against the person who expressed them. It would not be unusual for a son or daughter who is crying because of being 


\section{BOX 8.1}

\section{TRAITS COMMON TO ADULT CHILDREN OF ALCOHOLICS}

- Guess at what normal behavior is.

- Have difficulty following a project through from beginning to end.

- Lie when it would be just as easy to tell the truth.

- Judge themselves without mercy.

- Have difficulty having fun.

- Take themselves very seriously.

- Have difficulty with intimate relationships.

- Overreact to changes over which they have no control.

- Constantly seek approval and affirmation.

- Feel that they are different from other people.

- Are super responsible or super irresponsible.

- Are extremely loyal, even in the face of evidence that the loyalty is undeserved.

- Are impulsive.

- May tend to lock themselves in a course of action without giving serious consideration to alternative behaviors or possible consequences.

- Impulsively can lead to confusion, self-loathing, and loss of control over their environment. In addition, the person spends an excessive amount of energy cleaning up the mess.

Source: Adapted from Woititz, J. G. (1983). Adult children of alcoholics. Health Communications.

upset about their parent's being intoxicated to hear, "Stop crying or I'll give you something to cry about!" (Black, 1981, 2003). It is common for children who grow up in homes severely impacted by SUDs to carry dysfunctional communication patterns, problems in establishing intimate relationships, and particular personality difficulties into adulthood. As described by authors such as Janet Woititz (1983), Robert Ackerman (1981), and Claudia Black (1981), adult children of alcoholics (ACOAs) often struggle with the aftereffects of growing up in dysfunctional homes, and not surprisingly these aftereffects often are carried into their adult relationships both at home and at work. Box 8.1 presents a list of common traits of ACOAs as described by Janet Woititz (1983). What addiction counselors will often encounter is that not all ACOAs will manifest all of these traits; rather a few traits often come into focus as being more problematic.

\section{IMPACT OF SUBSTANCE USE DISORDERS ON FAMILIES AND FAMILY PROGRESSION}

It is important to point out that families experiencing SUDs vary in the intensity and level of dysfunction they experience. For example, research into alcoholic families concludes that those families who experience less interference with important family rituals (e.g., family dinner time, family vacations, and Christmas holiday rituals) tended to have children who were 
better adjusted and less likely to become alcoholics as adults (Steinglass, 1979, 1981; Steinglass et al., 1987). Wolin et al. (1980) also found there were three types of ritual patterns in alcoholic families: (1) intact rituals were those families that maintained important family rituals in spite of alcoholism; (2) subsumptive rituals existed in families that made adjustments or modifications in order to accommodate the drinking; and (3) disrupted family rituals were found in those families who were most impacted by their loved one's drinking. Families that managed to maintain intact rituals or subsumptive rituals tended to have better adjusted children and less likelihood of sons and daughters developing SUDs later in life.

Brown and Lewis (1999) discovered the following traits as being characteristic of families impacted by AUDs: (1) families experience distinct developmental stages as they progress from active drinking to recovery; (2) the environment or context of the drinking family is often traumatic and very harmful to children and adults; (3) the family system of the drinking family is often restrictive, rigid, and closed; and (4) in recovery, the unhealthy family system must collapse (i.e., the defensive structures that maintain the pathology of the entire family must change). In other words, once the alcoholic family member enters recovery, the entire family must also change, and this may be accomplished by abandoning dysfunctional family roles (e.g., enabling behaviors); (5) with the collapse of the unhealthy family system, adults then turn their attention to their own individual recovery (which often takes years); (6) children may be just as neglected or abandoned in early recovery as they were during active drinking especially as parents turn their attention away from the family and onto themselves; (7) families who embark on recovery are on a "dynamic process of difficult change which sometimes takes as a long as 10 years before all the pieces come together: a stable, healthy environment; a secure healthy family system and couple relationship" (adapted from Brown \& Lewis, 1999, pp. 17-24). Given that families impacted by SUDs vary in intensity and level of dysfunction, we would be remiss in not pointing out that many studies have noted correlations between child maltreatment, child physical and sexual abuse and neglect particularly in those homes most severely impacted by SUDs. Research also indicates that those children who grow up in severely dysfunctional SUDs homes often are at high risks for developing SUDs as adults (e.g., Halpern et al., 2018; Mandavia et al., 2016).

It is also important for counselors to take into consideration that families impacted by SUDs also experience a progression that often runs parallel to the progression that the alcoholic or addict parent experiences. According to Jackson (1954), families first experience Denial of the Problem. In this stage, families attempt to deny that their loved one has a drinking or substance use problem. They may blame external stressors (e.g., job stress and financial stress) for their loved one's drinking or drug use. For example, "Bob drinks every night because he's under so much pressure at work right now." This stage often coincides with the SUD family member's denial that their drinking or drug use is problematic. In the second stage, Attempts to Eliminate the Problem, the nonalcoholic spouse or partner begins to isolate from friends and extended family members. Here, the goal is to try to maintain the illusion of having "a happy home" to the outside world. In the third stage, Disorganization, the nonalcoholic spouse tries to cope with the ever-increasing tension in the home. This stage often finds frequent arguments, which may result in violence between spouses or partners. This would also be the stage where behavior problems in their children may begin. In the fourth stage, Attempts to Reorganize in Spite of the Problem, the nonalcoholic spouse or partner tries to hold everything together by making sure the rent or mortgage is paid, bills 
are paid, and basic needs are met (e.g., food, shelter, and clothing). Usually in this stage, the alcoholic spouse/partner is ignored based on resentful feelings that they cannot be trusted or counted on to fulfill responsibilities. In the fifth stage, Efforts to Escape are characterized by decisions whether to divorce or separate as the nonalcoholic/addicted partner tries to determine whether the marriage and family is salvageable and whether they will be able to sustain the life they have been experiencing. This stage usually corresponds to the person with the AUD "hitting bottom," at which point they may hopefully seek treatment. If this occurs, this leads to the sixth stage, Recovery and Reorganization of the Whole Family, as the entire family hopefully will engage in the treatment process (the alcoholic attends treatment and Alcoholics Anonymous [AA], while the nonalcoholic spouse and children also attend counseling and AA and/or Alateen). Even when the alcoholic spouse or partner enters treatment and begins recovery, not all families will engage in their own treatment. The seventh stage occurs if the alcoholic spouse does not "hit bottom" and either separation or divorce is sought. This stage is referred to as Reorganization of Part of the Family, referring to the fact that the nonalcoholic spouse and children usually begin to reorganize as a single-parent family.

As mentioned earlier, Brown and Lewis' (1999) research into families impacted by AUDs also found evidence of progressive family stages, which they define as: Drinking Stage, Transition Stage, Early Recovery, and Ongoing Recovery. During the active Drinking Stage, the family is basically in survival mode, as "daily family life becomes dominated by the anxieties, tensions, and chronic trauma of active alcoholism" (Brown \& Lewis, 1999, p. 14). Basically, the family is trying its best to cope and to hold things together. As the consequences of drinking become more visible to others and more difficult to resolve (e.g., DUI arrest, medical illness, and physical abuse), there is a growing need for secrecy and isolation from others, which unfortunately cuts the family off from outside sources of help or input from extended family, friends, and the community. As the family moves toward the Transition stage, there is a great deal of anxiety, tension, and apprehension as family members move into the "unknowns" of recovery and what will happen next. Brown and Lewis (1999) suggest that the parents need to get a foothold on each of their individual recoveries first before being able to work on their relationship as a couple. Two scenarios are common as couples move into Transition. The first is where the couple is in crisis (perhaps due to an arrest, disclosure of an extramarital affair, job loss, etc.), and often anger and hostility permeate the couple's bond with one another. The second scenario is where the couple has a workable, bonded relationship that had included active alcoholism, therefore, this couple is not in crisis as one or both partners move toward recovery. As the alcoholic partner moves toward abstinence, the couple may feel a loss of closeness. In Early Recovery, the family also faces many challenges as they experience many "firsts" without alcohol (e.g., first holidays, anniversaries, and birthdays) Couples will begin to find healthier ways to differentiate (separate from one another) as they let go of enabling or controlling dysfunctional roles. Physical and sexual intimacy within the couple's relationship also needs to be addressed and redefined. In addition, parenting roles and responsibilities will need to be redelineated. Sometimes, this is a difficult transition as the nonalcoholic parent had often assumed major responsibility for parenting roles and may resent the newly sober parent's interference in established parenting responsibilities. Finally, in Ongoing Recovery, families begin to experience a sense that things have slowed down and calmed down. But this does not happen with the passage of time alone. There are distinctions made between being "dry" versus "sober." An individual with an AUD is considered 
to be "dry" when they have stopped drinking but have not really embraced recovery, nor have they embraced the need for change. For example, a recovering alcoholic who has been working the 12 Steps of AA has probably begun to look within by making a "fearless moral inventory" of themselves and past alcoholic behavior (as would occur when doing a Fourth Step). Also, they may have made some attempts at "making amends" to their family for their inappropriate or destructive behavior during active addiction (as would occur when doing an Eighth and Ninth Step). A person who is "dry" never even gets close to self-examination or making amends to those family members they may have hurt. Families in ongoing recovery will still experience problems; however, the recovering family now has a framework with which to discuss and resolve problems in a way where every family member can be heard and respected. This would also be the point at which the family can seek treatment. Families in ongoing recovery hopefully can embrace the healthy family traits that were presented at the beginning of this chapter!

\section{TREATMENT ENTRY POINTS}

Given the family progression described earlier, it is important that counselors anticipate that there will be particular times when family members will reach out for help or when family counseling may be most helpful. Table 8.1 provides a description of some of these treatment entry points. Note that there are three essential times when families will access counseling for themselves or for their loved ones. The First Entry Point is when their loved one is actively drinking or using drugs. Here, the family is desperate to get their significant other to seek help for their SUD. Often, families have tried many strategies to get their loved one to accept treatment, so it is important for counselors to find out what the family has attempted and what has not worked or been helpful. It is also important for counselors to understand the varied emotional reactions that family members may have regarding their loved one's substance use. Some family members may be anxious or fearful, while others may feel angry or betrayed. Some family members may be shocked when they first become aware of their loved one's substance use. Counselors need to validate these various emotional reactions as being normal while at the same time attempting to get the family on the same page regarding what steps they need to take next. If the loved one refuses to seek help, there are several approaches that might be utilized to encourage a loved one to enter treatment. Johnsonian Interventions are designed to "confront the loved one with reality in a receivable way." Here, "confrontation" is not done aggressively, but rather in a spirit of love and concern. As described by Vernon Johnson (1973), who originated this technique, family members and loved ones are first gathered together to express their concerns. Family members, friends, and coworkers are then asked to list two or three examples where their loved one's drinking or substance use had caused them concern, in order that these incidents could be presented to their significant other in a loving, concerned manner. The SUD loved one is not included in these meetings. The family members and significant others are then coached as to when and how to present 
TABLE 8.1 Family Treatment Entry Points

\begin{tabular}{|l|l|}
\hline ENTRY POINT & GOAL \\
\hline 1. When loved one is actively using & $\begin{array}{l}\text { To assess current substance use or presenting crisis and to } \\
\text { engage family to work on goal encouraging loved one to } \\
\text { enter detox or or other treatment }\end{array}$ \\
\hline $\begin{array}{l}\text { 2. When loved one has completed } \\
\text { detox or residential treatment }\end{array}$ & $\begin{array}{l}\text { To determine how family can support aftercare and relapse } \\
\text { prevention plan. Also encourage family to work on their own } \\
\text { growth \& refrain from enabling and/or hypervigilant behavior }\end{array}$ \\
\hline 3. Ongoing recovery & $\begin{array}{l}\text { To establish new relationship patterns and healthy family } \\
\text { functioning }\end{array}$ \\
\hline
\end{tabular}

these concerns to their loved one with the goal that they will agree to enter treatment voluntarily. Counselors sometimes rehearse the intervention prior to actually meeting with the loved one. The intervention approach has been criticized as being coercive because if the loved one refuses help family members are encouraged to impose consequences designed to get their loved one to reconsider treatment. For example, one adult son's "consequence" was that he would call the police if his father continued to drink and drive.

Another less coercive approach that can be used at this entry point is called ARISE (A Relational Intervention Sequence for Engagement; Garrett et al., 1997; Landau et al., 2004), which involves three stages designed to encourage their loved one to accept treatment for their SUD. In the First Stage, a concerned significant other or family member contacts a counselor or treatment agency to obtain knowledge about treatment options. Here, the counselor assesses if there is a crisis needing immediate treatment by assessing the severity of the loved one's alcohol and/or drug use and encourages the family member to ask other family members and significant others for assistance. The substance users are asked to join the first in-person meeting. The counselor then proceeds to the Second Stage (only if the substance user has not entered treatment). Here, the counselor will work with the concerned family members and significant others to come up with clear and enforceable consequences for the substance user's continued alcohol or drug use. Stage 2 meetings (up to five sessions) also review efforts that have been attempted in the past, and strategies are developed that encourage the substance users to engage in treatment. Stage 3 is more confrontational, and in some ways is similar to a Johnsonian intervention; however, the expectation is that the substance-using loved one will have entered treatment prior to reaching this stage.

Finally, in some instances where families are at a point of desperation, civil commitment may be the only viable alternative. Presently, 38 states have some form of civil commitment laws that allow family members to petition the courts to commit their SUD loved one into a detox or inpatient-rehab type program (Cavaiola \& Dolan, 2016). Based on mental health civil commitment laws that allow the courts to commit individuals deemed to be a danger to themselves or others based on evaluations by licensed psychiatrists and/or psychologists, civil commitments for those with SUDs are also based on the supposition that these individuals are a danger to themselves and others by virtue of the fact that they are not able to make reasonable/rational decisions on their own behalf. The majority of SUD treatment requires individuals to sign themselves into treatment voluntarily; however, can we really expect that someone who has been using alcohol or drugs continuously for several years to make reasonable, rational decisions on their own behalf? 
The Second Entry Point is when the loved has completed a detox or residential treatment program and will be returning home (or may be entering a halfway house or sober-living facility). In each of those instances, it is important that families be involved in the aftercare planning as well as relapse prevention planning. If the loved one is returning home after completing detox or residential treatment, it is important that counselors assist families with the anxiety they are likely to experience now that their loved one is home. Anxieties usually center around whether or not their loved one can be trusted, will they relapse, will they be able and willing to take on responsibilities, will they attend AA or Narcotics Anonymous (NA) meetings, and will they be able to handle the stresses of returning to work or school? Also, it is helpful to have family discussions as to how they can best support their loved one's recovery (e.g., by removing alcohol and prescription medications from the home, by limiting access to large sums of money, and by initially providing transportation to AA or NA meetings and counseling appointments). At the second treatment entry point, it is important that family members keep their expectations realistic. Just because their loved one is abstinent, it does not mean that they will become a caring, loving, empathic individual overnight. This is also not the time to beat the loved one up emotionally for their wrongdoings from the past. The Third Entry Point occurs when families are looking to work on specific issues pertaining to their loved one's recovery. For example, if family members begin to notice dry drunk behavior (described in Chapter 13, Developmental Issues in Counseling) or if their loved one is not reconnecting with other family members, this may result in families seeking counseling. This may also be a time when family members are entering treatment in order to work through the pain and trauma that occurred as a result of active substance use. It is important for counselors to be aware that not all families are willing or ready to become involved in treatment at these stages. Box 8.2 provides information on when and where to offer alternative treatments to families especially during the aftercare or relapse prevention planning process. Appendix 8.1 provides a sample treatment regimen that might be used in inpatient or intensive outpatient (IOP) programs that offer family treatment services.

Also, counselors need to anticipate that families may present with resistance or ambivalence regarding their willingness to enter family counseling. It is common for counselors to hear, "It's his/her problem not mine, they need to deal with it." In instances such as these, it is helpful for counselors to validate the frustrations that family members have experienced and to hear out what types of struggles they have encountered. Families with a son or daughter experiencing a SUD may feel angry or frustrated by their behavior. Parents might explain how they have had to protect themselves or other family members from negative addictive behaviors as illustrated in the following example.

\section{CASE EXAMPLE: SEAN}

When Mr. and Mrs. Prescott's 28-year-old son, Sean, had finally agreed to enter a detox program, his parents were skeptical about his decision to seek help. Their first reaction was that Sean was entering detox only to avoid legal problems or to avoid paying money he owed to his drug dealer. For the past four years, the Prescotts describe their life as "a living hell" in which they had to padlock their bedroom after Sean had stolen his father's watch and his mother's pearl necklace to pawn for drug money. Last Thanksgiving, when the Prescotts hosted a large gathering of grandparents, aunts, uncles, and cousins, Sean 
was up in the bedroom rifling through their guests' purses and coats looking for money and credit cards. Only one of Sean's aunts said anything about the thefts to Mrs. Prescott, who felt humiliated. When Sean's primary counselor called the parents to try to arrange a family counseling session, his parents were angry, frustrated, and wanted no part in Sean's treatment. This had been Sean's third detox within the past year; however, Sean's counselor heard the parent's frustrations and convinced them that, if she was to be of help to Sean, she needed them to be her allies in the process. The Prescotts agreed to come in to discuss an aftercare plan with Sean. Both the parents and the counselor hoped they could convince Sean to go to a long-term residential program followed by a halfway house or, at very least, an intensive outpatient (IOP) program and Oxford House or sober living facility. At one point in the session, Mrs. Prescott said to Sean that she could not go on like this, "feeling like a prisoner" in her own home, adding, "your addiction is sucking the life-blood from me and your father."

\section{BOX 8.2}

\section{WHEN AND WHEN NOT TO INVOLVE FAMILIES}

Involve family members when...

1. they accept their loved one's SUD as a chronic disease and do not blame themselves;

2. they are willing to be supportive of their loved one's recovery;

3. they accept that, even though there may have been past treatment failures, they need not be cynical or skeptical that recovery cannot be attained;

4. they are willing to let go of enabling behaviors and work on themselves;

5. they are willing to attend $A A / N A$.;

6. family members are willing to take direction from their loved one regarding what they consider helpful, for example, whether to remove all alcohol or prescription medications from house.

\section{Consider alternative treatment when...}

1. the family member(s) are actively using or have an active SUD;

2. the family members are cynical and/or skeptical of their loved one's recovery;

3. the family member views their loved one as manipulative and incapable of change;

4. the family member holds too much anger toward their loved one for past betrayal;

5. the family member blames themselves for their loved one's SUD and are, therefore, unwilling or unable to let go of enabling behavior;

6. the family member remains hypervigilant regarding their loved one's recovery efforts and finds it difficult to allow their loved one to work their own program of recovery;

7. in the instances noted earlier, it will be more helpful to refer family members for their own individual counseling and/or to AA or NA. 
Although it is sometime difficult to get families to agree to counseling, it is imperative especially when coming up with a collaborative treatment plan. It is imperative for counselors to remember that, with SUDs, all family members are impacted; therefore, nonaddicted family members and significant others will need to re-examine and re-establish healthier roles and boundaries. Also, keep in mind that family members can either support or sabotage future treatment planning, therefore, it is important they are part of the planning process and have the opportunity to become part of the solution rather than part of the problem (Cavaiola, 2000).

The ability to manage family resistance is an important skill for counselors to possess. There are many instances where families may have had negative experiences with prior treatment providers, and it is important to hear out those complaints in order to work toward collaborative treatment planning (Anderson \& Stewart, 1983). Yet, it was also essential for Sean's counselor to validate the parent's feelings of frustration, fear, and skepticism. The Prescotts were clearly overwhelmed and did not know what to do to help Sean accept his SUD and to accept the necessary treatment. Family counseling can provide a helpful environment to explore these feelings and to process them in a useful manner.

\section{FAMILY COUNSELING MODELS AND TECHNIQUES}

Just as there are theoretical models and counseling techniques used for helping individuals (e.g., psychoanalytic, behavioral, Gestalt, and cognitive behavioral), there are also models that are more specific to working with couples and families. In this section, we will be presenting four of those family models (Family Systems, Structural Family Therapy, Family Disease Model, and the Behavioral Model) and some of the family counseling techniques that correspond to these various theoretical models.

\section{Family Systems Model}

The Family Systems model was originally developed by well-known theorists such as Jay Haley and Murray Bowen. According to Bowen (1978), families are essentially social systems that are bound by a precise and predictable set of rules or dynamics that function throughout the entire family often for up to three generations (Bradshaw, 1995). What is essential to this model when applied to SUDs is that any disturbance to part of the family (or system) will impact all family members, and therefore all members of the family system will react in an attempt to try to maintain balance or homeostasis. What's interesting about the concept of homeostasis is that it can occur in healthy family systems as a way to maintain healthy family goals or in dysfunctional family systems as a reaction to changes that may appear as threatening. Here are two scenarios of family homeostasis.

\section{CASE EXAMPLE: JASON}

Scenario 1: Jason is 18 years old, a senior in high school, and currently living with his parents and two younger siblings, a 15-year-old brother, Tim, and a 13-year-old sister, Jamie. Jason has been snowboarding since he was 6 years old and began competing when he was 11 . Because he was winning local competitions, Jason's coach recommended that he attend a special 
school at one of the ski/snowboard resorts that would provide him with expert coaching and would increase his chances of competing nationally and perhaps even internationally, which would put him on track to compete in the Olympics someday. In order to help make this happen, Jason's parents worked extra hours to bring in more income to pay for their son's school and extra coaching. Jason's father worked in a local factory in Vermont, and his mother worked as an elementary school teacher. Fortunately, both of Jason's siblings were supportive of the extra attention that he was receiving. Tim was also an avid and talented snowboarder, and Jamie was the star of a travelling soccer team, so they appreciated all the time Jason put into improving himself. Jason's entire family was on board with supporting Jason's goals of someday competing in the winter Olympics.

Scenario 2: In the last scheduled competition of the winter snowboarding season, Jason suffered a major injury that required extensive knee surgery. Both Jason and his parents are worried that the injury will jeopardize his scholarship. Jason is anxious that he needs to get back to practicing in order to avoid losing his scholarship. Jason's doctor prescribes an opiatebased analgesic (painkiller) in order to help him with the pain following his surgery. Jason goes through the prescription quickly and asks his doctor for a refill, which she reluctantly prescribes. Within a month, Jason is dependent on the painkillers. His parents are worried that Jason is pushing himself too hard by constantly working out. Within a few months, Jason's doctor refuses to prescribe more painkillers and recommends that he increase his physical therapy sessions. Jason begins to buy prescription opioid pills from a local drug dealer. Also, Jason's father received notice that the factory where he has been employed is closing, and he will need to go on unemployment.

In the two scenarios described, we see a family struggling to maintain homeostasis. In the first scenario, Jason's family is doing everything to support his goals of attending a special school for snowboarding. This is an example of a healthy homeostasis in which the entire family is supportive of one another and therefore supportive of Jason's goals. Also, in this first scenario,

\section{LEARNING ACTIVITY 8.4 ASSESSING FAMILY DYNAMICS}

For this Learning Activity, watch any one of the films listed in the "Resources" section at the end of this chapter. See if you can identify the dynamics (i.e., interactional patterns) among the key family members and also identify how these family interactions have been impacted by SUDs. Jason's family embodies many of the healthy family traits described earlier in this chapter. However, in the second scenario, Jason suffers an untimely injury and turns to opiate painkillers, which causes his life to unravel. Compounding the financial woes of the family are worries that Jason's father may be losing his job as his factory may be shutting down soon.

One of the basic principles of the Family Systems model (and a healthy family trait) that Bowen proposes is the concept of differentiation and separation. Healthy families value independence and autonomy, and we see this in the first scenario, where Jason's parents are doing everything possible to prepare to successfully "launch" him off to a specialized school for snowboarding. In ideal circumstances, sons and daughters are encouraged to "leave the nest" as part of their overall development into emerging adulthood. However, think about how SUDs impact on the differentiation process. 
The Family Systems model can also be applied to couples. We see this both in active addiction as well as in recovery. During active addiction, couples also experience a need to maintain homeostasis. This usually takes the form of the nonaddicted spouse or partner taking on codependency roles, most often by becoming the enabler or caretaker of their addicted loved one (such as calling their loved one's boss to make excuses for them not being able to make it into work, when in fact they are too hungover). It is common for these homeostatic patterns to exist over the course of many years. Consider a situation in which the addicted partner becomes clean and sober. During active addiction, homeostasis suggests that there will be a certain predictability to how problems are managed. Here, recovery becomes an unknown, and with it comes a great deal of anxiety and apprehension for both partners. The nonaddicted spouse or partner may fear their partner may no longer need them or may fear they may meet someone in AA or NA and fall in love with that person. It is not unusual for the nonaddicted partner to resent their loved one attending AA or NA meetings. A common complaint often voiced by spouses/partners is: "First I lost you to alcohol or drugs and now I've lost you to AA/NA!" In response to these fears, apprehensions, and frustrations, the spouse of a newly sober alcoholic who was attempting to do a "90 in 90" (i.e., attending 90 meetings in 90 days) purchases a monogrammed whiskey flask for her husband for a Christmas present. Although to an outside observer this act seems insane, the purchase of the whiskey flask was actually an attempt to return to the dysfunctional homeostasis that existed prior to the husband getting sober and attending AA.

It is important to consider that there are many instances where both partners are actively using alcohol or drugs. This was the focus on the HBO documentary Dope Sick Love (Conte, 2005), which chronicles three couples impacted by SUDs. What becomes obvious is that it is often impossible for couples to recover together. As one partner makes attempts to recover, the other partner often becomes frightened or threatened by this change, and they will pull their partner back into active substance use. Again, this is an example of how powerful dysfunctional homeostasis can be. Cavacuiti (2004) describes the challenges that these couples face when much of their relationship is formed around their substance use. In addition, Cavacuiti found that these couples most often do not fit the classic patterns of codependency (described earlier) and instead finds that their relationships are often complex and varied. He identifies some couples as "concordant couples," referring to those couples whose lives are equally taken over by their drug of preference. Also, Pivnick et al. (1994) studied women participating in methadone programs and found the majority were involved in romantic relationships with men who were also substance users.

Although the Family Systems model was initially developed as a generalist theory, meant to describe all families, it was not until the 1970s that this model began to influence the drug and alcohol treatment field. Steinglass was one of the first researchers to notice repetitious patterns in the family interactions of his clients, which led him to conclude that SUDs had a stabilizing or adaptive function within these families that helped maintain equilibrium (or homeostasis) and also helped solidify family roles and ways in which these families interacted (e.g., expression of emotions and conflicts; see Steinglass, 1979, 1981; Steinglass et al., $1977,1987)$ Steinglass also found in instances of active parental alcohol use that these families tended to be more rigid both in terms of family roles and interactions. Therefore, counselors working with families in active addictions may find roles and interactions that are very entrenched and often predictable. 


\section{Family Systems Techniques}

According to Family Systems theory, substance use may symbolize a maladaptive attempt to maintain a dysfunctional homeostasis. It is not coincidental that problems related to substance use may arise during critical periods in which the family is attempting to negotiate key developmental milestone (e.g., like "launching" an adult son or daughter into the world). As mentioned earlier, in healthy families, differentiation or separation between a young adult son or daughter and their parents is encouraged and supported. However, when a SUD impacts a son or daughter, healthy differentiation becomes impossible and is often replaced by enmeshment (or fusion) as parents find themselves in constant fear of overdose or imprisonment and are convinced their son or daughter will never be able to make a successful transition toward becoming an independent young adult. Because of these tensions and conflicts, this may be a time at which the son or daughter acts out and gets arrested or a DUI. Nothing stops healthy differentiation dead in its tracks like an arrest or some other substance-related crisis. It is at this point when the family often rallies around their son or daughter to try to fend off potential jail or prison time. When family counselors begin to counsel families in the aftermath of an arrest, the therapeutic work must eventually shift the focus away from the arrest and to how the family can address the substance use issues in order to move forward. In order to accomplish this goal, family counselors utilize a few different techniques. The first is joining. Here, the family systems counselor is attempting to develop a therapeutic alliance with the family in order to gain their trust and confidence. The counselor joins the family in two ways: first, by supporting the family system and its member (by making a connection with each family member). Joining also involves the family counselor asking each family member what their perception of the problem is. (This is why it is very important to have all family members present, as we have witnessed instances where a younger sibling correctly perceives the dysfunction within the family and speaks the truth, while other family members may be invested in maintaining a dysfunctional homeostasis. For example, after listening intently during a family session, an 8-year-old younger sister finally blurted out "nothing will change as long as Dad and my older brother are drinking buddies." The younger sister was pointing out an unhealthy alliance or collusion between her father and older brother.) Once a connection is made and the family gains trust in the counselor, the counselor then can challenge the family system. The counselor must be able to tell each family member that they understand their perception of the problem and also can state with confidence that there are ways to address the problems (Stanton et al., 1978).

The second technique used by Family Systems counselors is called restructuring. Here, the family counselor attempts to challenge the homeostasis by changing the bonding and power alignments among various family members. In order to accomplish these goals, counselors will use techniques such as contracting (an agreement to work on particular substance use issues before proceeding to work on other problems), reframing (here, the counselor encourages family members to understand how the substance use serves an important function or purpose within the family), and enactment (here, the family counselor is asking the family to discuss the substance use problem with one another as they might at home, while the counselor observes the dynamics between family members). Restructuring can be a valuable tool when working with families in that it provides family members an opportunity to experience roles from an entirely different perspective. 


\section{CASE EXAMPLE: BRITTANY (FAMILY SYSTEMS)}

Brittany is a single woman in her early 20s who is currently living at home with her biological mother and father, her maternal grandmother, and an older brother and two younger sisters in West Virginia. Brittany began using alcohol and marijuana when she was around 13 years old; however, she then progressed to using OxyContin (an opioid analgesic or painkiller), which she ingests orally. There are times when Brittany would "cook" the OxyContin pills down to liquid form in order that she could inject it intravenously. Although Brittany has used other substances in the past eight years, she identifies OxyContin as her current primary drug. Her entire family is aware of her prescription opioid use and are very worried that she will overdose or be harmed when she goes out to buy the drug on the street from drug dealers. Brittany also admits to having used black-tar heroin when OxyContin is unavailable, and she admits to stealing pain medication from her father, who sustained a work-related injury while working as a coal miner.

\section{Case Conceptualization: Brittany}

Brittany's opioid use disorder seems to be maintained by several core issues. First, Brittany reports that she was sexually molested by an older, male cousin when she was around 13 years old, which coincides with the initial onset of her using alcohol and marijuana. Brittany was afraid to tell her parents because she worried that they would not believe her. The other core family issue is that when Brittany was 11 years old, her older brother Jon was murdered in a drug deal that had gone bad. This had a devastating impact on Brittany's parents, who blamed themselves for Jon's death because he had been living at home at the time, and the parents felt they could have done more to get Jon into treatment or somehow motivate him to accept help. Now every time Brittany leaves the house, her parents go into "panic mode," as they fear that Brittany will end up being murdered like Jon. Another core issue is that Brittany was raped by three men from whom she had purchased heroin. She has very little recollection of that night and thinks she may have been given a "date rape drug" like gamma hydroxybutyrate (GHB) or Rohypnol. Finally, Brittany admits that the more her parents try to restrict her from going out of the house, the more she rebels by sneaking out of the house at all hours of the day or night.

Brittany's family lives with the trauma of death hanging over them on a daily basis. They never really forgave themselves or grieved Jon's death, and now they live in utter fear that the same thing will happen to Brittany. Brittany's parents had gone into a deep depression after Jon was murdered. As a result of their dread that something may happen to Brittany, Brittany's father rationalizes that if he gives her his painkillers it's better than her going out on the street to buy heroin from a drug dealer who might end up raping or murdering her. This is a family who find themselves in what is sometimes referred to as a "family crucible" in which all members are locked into a pattern of destructive behaviors from which they see no way out. Brittany's siblings very much want her to seek help. Her older brother, Frank, especially feels that his parents have unintentionally become enablers to Brittany's addiction and has concluded that "nothing will change, unless Mom and Dad wake up and begin to make major 
changes." Brittany's younger sister, Eva, is also very worried about Brittany and constantly fears that something horrible will happen to her. Eva tends to keep these feelings bottled up and binge eats when she feels anxious. A word of caution: we do not want students to assume that everyone suffering with SUDs has experienced several major traumas such as Brittany. As discussed in Chapter 2, An Overview of Etiological Models, there are several possible etiologies or causal factors that may account for why individuals develop SUDs.

There are several ways these Family Systems techniques can be utilized in counseling Brittany's family. Given the murder of Brittany's older brother Jon, Brittany's parents have tried to stabilize the dysfunctional homeostasis created by Brittany's opioid use by focusing all of their efforts on making certain that Brittany does not meet a similar untimely death. Yet, just as Brittany is powerless over her opioid use disorder, so too are her parents and siblings. Because the parents are so focused on Brittany, it is almost as if their other daughter and son are nonexistent.

The real challenge for Brittany's parents and siblings will come once Brittany completes detox and residential treatment and begins to work on her recovery. Often parents and siblings are at a loss as to how to best help their now-recovering loved one, so the tendency is to go back to old roles or ways of relating to one another. This too is an example of homeostasis at work because the family's tendency is to revert to old patterns of interacting because they have no frame of reference of how to interact with Brittany now that she is clean/sober. It is common, therefore, for parents to become hypervigilant, watching their son or daughter's every move, instead of focusing on their own recovery. No wonder that family counselors often refer to this initial period when a loved one comes home from treatment, as walking on eggshells because of the tension created by not knowing how to act toward one another in healthier ways. Naturally, this is where counseling becomes vital, especially during these early days/weeks/months of recovery.

\section{Structural Family Model}

Structural Family Theory was originated by Salvador Minuchin and his colleagues at the Philadelphia Child Guidance Clinic (PCGC) in the 1980s. Initially, Structural Family Therapy was utilized to treat a number of child/adolescent behavioral problems for everything from bedwetting to eating disorders to fire-setting. Essentially, Structural Family Therapy addresses problems in functioning within a family. In order to bring about change within the family, Structural Family therapists will first "join" with the family in order to understand the invisible rules that govern its functioning. The counselor takes note of how family members relate and interact with one another which is referred to as mapping. The family counselor ultimately attempts to change the dysfunctional relationships within the family, causing it to stabilize into healthier patterns.

When Stanton (1979) and Stanton and Todd (1982) joined the PCGC team, it was with the purpose of applying Structural Family Theory and accompanying techniques to counseling heroin-addicted young adults and their families. In their work with families, Stanton and Todd (1982) made several important observations regarding this population. First, they found that although they were often counseling young adult men and women, these individuals often had a great deal of contact with their family of origin (i.e., parents). See Box 8.3. It is often assumed that as one progresses more deeply into their addiction, the more isolated the addicted loved one become from others. However, this 


\section{BOX 8.3}

\section{FAMILY TIES}

It is often assumed in homes that are impacted by SUDs tend to result in disconnections between family members. Such would be the case with adult sons or daughters who are experiencing substance use disorders (SUDs; Chein et al., 1964). However, the majority of research studies and anecdotal clinical accounts suggest very much the opposite, i.e., adult sons and daughters actually do have regular contact and involvement with their parents (Stanton \& Todd, 1982; Stanton et al., 1978). Yet, it is also common for these families to have experienced regular family disruptions (e.g., divorce, child abandonment, and separations). Watch any episode of A \& E's reality TV show Intervention in order to gain an appreciation for the types of family disruptions that are common in SUD families. However, Cervantes et al. (1988) also found that among 98 consecutive admissions to a urban-based methadone maintenance clinic, $67 \%$ of the adult clients currently lived with a family member, $26 \%$ lived with a parent, and $75 \%$ indicated they had close ties with their mothers. Interestingly, in a study of 532 males with opioid use disorder, clients those who reported less frequent weekly heroin use had more frequent contact with their family of origin, their biological parents, and their grandparents (Tseng et al., 2010).

was not the case with families impacted by opioid use disorders (Stanton \& Todd, 1982). This finding also holds true with individuals impacted by SUDs other than opioid use disorders especially for individuals younger than 35 years. Here, it was discovered that $60 \%$ to $80 \%$ of these young adults had contact with one or both parents on a daily basis (e.g., Bekir et al., 1993; Cervantes et al., 1988; Stanton, 1997).

\section{Structural Family Techniques}

Stanton and Todd (1982) recommend a six-step structural model for counseling families. This model assumes that an adolescent or adult son or daughter is the IP who presents with a SUD. The six-step model follows the following sequence:

1. Problem Definition \& Contracting: In defining the "problem" the “__ism" label (i.e., alcoholism) is not as important as coming up with a behavioral definition of the problem and behavioral change. Counselor approach: (a) establish an alliance with senior family members, (b) assume a nonblaming stance, (c) SUD should be labeled a "family problem" so everyone works toward the goal of abstinence, and (d) disease/genetic model should be explained as a means of reducing guilt/blame/shame.

2. Establish a Context for a Chemical Free Life: Cessation of alcohol or drug use is a prerequisite for further treatment. Discuss how this will occur within the family and how the family can support this context: (a) refer family to 12-step groups such as Alcoholics Anonymous and Narcotics Anonymous, (b) refer couples to spousal support groups, (c) have no expectations of change (e.g., it is too early in the process to expect change to occur), and (d) be prepared to deal with unresolved grief/loss issues.

3. Ceasing Substance Abuse: This becomes the "moment of truth" as the addicted family member realizes that they must choose between their family and SUD: (a) arrange for detox if necessary and (b) continue to support family and their recovery even if the addicted family member refuses further treatment. 
4. Managing Crisis \& Stabilization: This is often the most frightening stage. Involves dealing with life without substance, changing family roles, and re-establishing trust.

5. Family Reorganization \& Recovery: At this stage, the family reorganizes itself as a recovering family with more appropriate boundaries, with parents in charge, and with the beginnings of healthy separation, as the now-recovering son or daughter is able to assume healthy responsibilities in order to become more independent.

6. Follow-Up: The counselor will periodically follow-up with the family to ascertain how they are functioning and to plan how they will manage relapses or any other setbacks.

This six-step model provides a framework by which counselors can assist families to move toward change. Even if the family member with the SUD refuses treatment, it is important to continue to work with the family. There is a saying among family systems counselors, "Work with the part of the family that's workable." In other words, although some family members may want no part of treatment or counseling, counselors can still be helpful to those family members who do desire help and change.

If a family counselor were to utilize Structural Family techniques to working with Brittany's family, the counselor might try to restructure the family by placing the older brother in charge of Brittany (e.g., by taking her to NA meetings and helping her to find a job) and giving permission for her parents to focus on themselves by attending NA or AA groups specific to parents and grandparents. The Structural Family counselor might also contract with the family to refrain from providing Brittany with money and pain medication. Finally, a family counselor might reframe the parent's enabling behavior as being an example of their willingness to do just about anything to keep Brittany alive. When the counselor feels that they have sufficiently joined with this family, she may introduce another "life-saving" approach which would be to seek other forms of intervention even if it means that Brittany will be court-mandated to treatment.

\section{Family Disease Model}

The Family Disease Model grew out of AA, the 12-step program which began in the 1950s to assist families and friends of individuals suffering from AUDs. According to folklore, when AA was in its early beginnings, Lois Wilson, the wife of Bill Wilson (one of the cofounders of AA along with Dr. Bob), would meet with the wives and girlfriends of the men attending the AA meeting (which at the time were being held in Bill and Lois's apartment in New York City). The essence of the Family Disease Model is that alcoholism not only impacts the alcoholic but everyone in their immediate social circle (i.e., family and friends). These family members and friends often fall into roles of codependency which is viewed as a "recognizable pattern of personality traits, predictably found within most members of chemically dependent families" (Cermak, 1986, p. 1). Co dependency traits often includes (a) low self-esteem or self-esteem that is based on controlling the alcoholic loved one; (b) feeling responsible for meeting the needs of other's before oneself; (c) experiencing anxiety and boundary issues around intimacy and separation; (d) being enmeshed in relationships with the alcoholic loved one; and (e) having other symptoms such as denial, depression, anxiety, or hypervigilance (Cermak, 1986). The Family Disease Model also hypothesizes that families adopt several different types of codependency roles as coping strategies. These roles are often seen as survival roles in the dysfunctional alcoholic family. 
In addition, there is a body of research which has examined the impact of SUDs on family and child functioning (e.g., Collins et al., 1990; Jacob, 1992; Rotunda et al., 1995; West \& Prinz, 1987). There are characteristic roles for both the spouse partner and the children as described in Table 8.2.

The aforementioned roles in Table 8.2 represent a variety of codependency roles. For example, the enabler attempts to hold the family together by making excuses when their loved one is unable to make it into work or unable to pay bills. Some parents even supply their addicted sons or daughters with drugs in order to avoid them needing to purchase drugs from dangerous drug dealers. The controller tries to regulate their loved one's substance use by controlling their access to money or transportation to go out to purchase drugs or alcohol. The placater attempts to reduce tension in the home by acquiescing to their loved one's every demand. The placater will do anything to keep the peace within the home. The waiverer, on the other hand, will threaten their loved one with dire consequences (e.g., kicking them out of the house) if they drink or use drugs "one more time," only to acquiesce or cave once the next substance use episode occurs. The waiverer talks a good game but usually does not hold to their threats. The martyr often uses guilt trips in order to get their loved one into stopping their alcohol or drug use. They will usually complain incessantly to others how their life has been ruined by their addicted love one, but rarely, if ever, will do anything about it. What is common in any of the aforementioned spousal or partner roles is that although the behaviors are meant to somehow try to change their loved one, these strategies usually do not work, which then only adds to the already-existing stress levels. It should not be surprising that codependents often are plagued by many stress-related illnesses (Whitfield, 1989).

The child roles are also considered to be survival roles or attempts to cope in a dysfunctional family system that has been ravaged by SUDs. For example, the family hero will try to detract from parental conflicts or tension by calling attention to their latest accolade or award. Family heroes are often the oldest child within the family, and as adults, it is common for them to assume leadership roles or other positions of responsibility or to go into helping professions (e.g., medicine, social services, and counseling). The family scapegoat draws attention to

TABLE 8.2 Spousal/Partner Roles

\begin{tabular}{|l|l|}
\hline Enabler & $\begin{array}{l}\text { The enabler tries to hold the family together by taking over the responsibilities of } \\
\text { their addicted spouse/partner. The enabler encourages or makes possible negative } \\
\text { behaviors }\end{array}$ \\
\hline Controller & $\begin{array}{l}\text { The controller attempts to regulate or limit their loved one's access to money, credit } \\
\text { cards, and checkbooks in an effort to prevent him or or from buying alcohol or drugs }\end{array}$ \\
\hline Placater & $\begin{array}{l}\text { The placater tries to maintain the peace in the family at all costs, by keeping tensions } \\
\text { or conflicts from mounting. To accomplish this, the placater gives in or acquiesces to } \\
\text { their loved one's every wish }\end{array}$ \\
\hline Waiverer & $\begin{array}{l}\text { The waiverer vacillates or flip-flops between threatening their loved one with divorce, } \\
\text { expulsion from the home, etc., one minute while withdrawing the threat the next } \\
\text { minute, as if nothing happened }\end{array}$ \\
\hline Martyr & $\begin{array}{l}\text { The martyr blames their substance-using significant other for creating all their misery } \\
\text { and lot in life. While the martyr is adepts at blame and finger-pointing, they rarely do } \\
\text { anything about their plight, other than to complain }\end{array}$ \\
\hline
\end{tabular}


themselves by negative acting out behavior that is displayed at school or in the community (which often results in legal difficulties). The scapegoat is particularly adept at getting into trouble at the most inopportune moments which serves to divert attention from parental conflict. If Mom and Dad are fighting at the dinner table, it is the scapegoat who will knock over their milk in order to draw attention away from the argument. The family clown-mascot role is characterized by attempts to diffuse parental conflicts by joking or comic stunts to draw attention away from whatever tension the family may be experiencing at the moment. The lost child is the quiet child, who withdraws from family conflict, hides in their room, and otherwise keeps a low profile. These children tend to internalize family tensions and conflicts. Although these alcoholic family roles are often attributed to Sharon Wegsheider-Cruze (Wegsheider, 1981), they were originally developed by well-known family therapist, Virginia Satir (1988; Satir et al., 1988) who was working with families impacted by cancer. She discovered that children would adopt these roles after one of their parents had been diagnosed with cancer. It is noteworthy that children in stressful family situations will tend to adopt similar survival roles.

\section{Family Disease Model Techniques}

Since this model examines how SUDs impact all family members which then results in all family members adopting particular roles in order to cope with the impact of the disease, it is important that counselors first explore how these roles play out with each particular family member without blaming or judging the family. Instead, it is important that counselors empathizes with the family's attempts to cope with the SUD before encouraging them to change these attitudes and behaviors. For example, trying to get a spouse or partner to attend AA or NA will be a difficult task if they do not see a rationale for the recommendation that they attend meetings.

The essential message that would be given to the nonalcoholic, nonaddicted spouses, partners, and/or family members attending AA or NA would be "detach with love, take care of yourself while letting go and allowing your loved one to take care of him or herself." That can be a tall order to someone who has been accustomed to being the caretaker. Therefore, it is important that counselor exercise patience as well as empathy. With children, especially those who have taken on the role of the family hero, it is important for counselors to give them permission to be a child or adolescent and not have to take on the burden and stress of constantly being the overachiever.

With regard to Brittany's family (described earlier), using a Family Disease Model perspective, it becomes clear to the counselor that both Brittany's parents and her siblings have adopted particular roles in response to her opioid use disorder. Her parents have obviously become Brittany's enablers while her older brother Frank has stepped into the "hero" role, shortly after his brother's death, while Brittany's sister, Eva, has become the "lost child" of the family. Frank is usually very outspoken about how "Brittany has ruined the family," while Eva usually does not express her apprehensions. The role of the family counselor would be to try to encourage the family to let go of unhealthy codependent family roles and to adopt healthier roles. For example, rather than enabling Brittany by giving her money and painkillers, they could help her by encouraging treatment. Overall, the message to the family members is "take care of yourself first." This is not dissimilar to AA or NA's recommendation that family and significant others "detach with love." 


\section{Behavioral Family Model}

Behavioral models examine ways in which families or partners inadvertently or unintentionally reinforce their loved one's drinking or drug use behaviors. There have been several research studies that have determined verbal communication, verbal output, and attention which increases around the topic of drinking in couples where there is an alcoholic partner (Becker \& Miller, 1976; Billings et al., 1979; Frankenstein et al., 1985; Hersen et al., 1973). Interaction patterns also differed depending on the gender of the person with the AUD. For example, Haber and Jacob (1997) found that when a woman's alcoholic drinking tended to result in more relationship problems whereby these couples experienced more negative interactions than would occur with a male's alcoholic drinking. Generally, men with AUDs experienced fewer negative interactions with their partners when they were drinking. It is also common for spouses to withdraw from their alcoholic spouse when they are drinking believing that this will somehow encourage abstinence, however, research suggests quite the opposite, that is, that assertive and engaged spousal coping was associated with reduced drinking (McCrady et al., 2002; Moos et al., 1990; Orford et al., 1975).

Barbara McCrady has done extensive clinical and research work with couples experiencing SUDs and has developed several techniques for counseling couples where one or both partners are actively using. Her stance is that couples treatment should begin with the very first contact or first session. (The prevalent view in the addictions treatment field for many years was that the addict or alcoholic needed to establish stable and consistent abstinence/recovery first before any couples or family counseling could be initiated.) Working with couples from the onset of treatment, however, provides several advantages. First, it allows both partners to participate in the behavioral change process rather than focusing just on individual partner who has the SUD. Second, couples therapy also allows the couple to reinforce one another (both in session and between sessions) for positive behavior change and to find shared activities that do not revolve around drinking. Third, couples find they are able to communicate more positively with one another, Fourth, couples who participated in couples therapy were better able to identify the role each other plays in maintaining or reinforcing substance use. Fifth, couples therapy allows partner to problem-solve and resolve conflicts together (McCrady et al., 2012, 2013). Here, research indicates that couples who have participated in counseling together had lower rates of domestic violence than those who participated in individual therapy alone (O'Farrell et al., 2004; Schumm et al., 2009). McCrady et al. (2012) discovered that similar to how individuals impacted by SUDs make several key changes as they are going through addictions treatment, so too does the significant others or partners. For example, family members and significant others who participate in couples/family counseling often benefit by

(a) recognizing that their loved one has a SUD that requires change;

(b) understanding and supporting positive behavioral changes in their partner;

(c) increasing awareness of family member's patterns of behaving and thinking; that might trigger substance use in their loved one;

(d) developing emotional, cognitive, and behavioral skills that enhances motivation to change and to support positive changes;

(e) developing expectations of positive behavioral changes (derived from McCrady et al., 2012, 2013) 


\section{Behavioral Family Techniques}

From a behavioral perspective, family counselors are interested in how the family may be inadvertently positively reinforcing alcohol or drug use behaviors. The best example of this is how Brittany's parents would give her money and painkiller medications in order to dissuade her from going down to unsafe neighborhoods to purchase prescription opioids and/ or black-tar heroin.

A Behavioral Family counselor would focus on changing the reinforcement patterns such that Brittany would be rewarded for any positive behaviors (e.g., days when Brittany does not use, or when she goes out looking for a job). It is important that Brittany not be given money as a reward because that may be a trigger for her to go and purchase prescription opioids or heroin, so instead it would be recommended that the parents reward Brittany with verbal praise or making her favorite dinner or taking her out for a movie. Behavioral Family counseling would be especially helpful once Brittany detoxes and completes a residential treatment program by helping the family to develop new ways to relate to one another in which the parents could reinforce Brittany's efforts to work on her recovery such as going to NA meetings or talking with her sponsor. Through Behavioral Family and Couples counseling, significant others are taught how to refrain from conflictual communication (which could potentially trigger a relapse) and to focus more on reinforcing positive behaviors. For example, rather than a spouse or parent scolding their loved one for not attending an AA or NA meeting, they would be taught to comment positively when their loved one does attend a meeting by saying something like, "Whenever you come home from a meeting, you seem happy, like a weight's been lifted off your shoulders!"

\section{Community Reinforcement and Family Training}

Community Reinforcement and Family Training (CRAFT) was originated by Robert Meyers, $\mathrm{PhD}$ (Meyers et al., 2001), for the purpose of helping families cope with a loved one's SUD. CRAFT utilizes several techniques to help families cope. First, CRAFT helps families to refrain from contentious arguing and criticisms and instead to use more positive communication skills and to look for "windows of opportunity" when concerns about alcohol or drug use can be expressed without criticism, anger, or judgment. Instead of "you were drunk and stoned when you came home last night. You're going to end up being a drunk and druggies just like your father," CRAFT would recommend to wait for a more opportune or receptive moment to say something like "I'm concerned because you seemed to have a lot to drink last night." By teaching families how to communicate more positively, they are thereby avoiding critical, name-calling, blaming, and other negative statements. Instead, family members are encouraged to utilize the following communication skills: (1) be brief (i.e., avoid lengthy lectures or preaching, instead make statements brief and to the point); (2) be positive (state what behaviors you want, rather than criticizing, blaming or overgeneralizing); (3) be specific (rather than making vague statements, describe the behaviors you would like to see); (4) describe your feelings in a calm, nonjudgmental, and nonaccusatory way; (5) offer an understanding statement (e.g., express empathy and understanding to your loved one and their struggle with SUDs); (6) accept partial responsibility for your loved one's behavior (family members may cite a small piece of the problem for which they can take responsibility, e.g., 
"I know I've been too lenient and looked the other way, hoping that things would get better, that's my fault."); and (7) offer to help (by asking your loved one, "How can I best help you?" especially in an honest, genuine way; Center for Substance Abuse Treatment [CSAT], 2006; Smith \& Meyers, 2004).

CRAFT also emphasizes the use of natural consequences. For example, instead of getting the intoxicated loved one into bed when they come home under the influence, it is suggested to leave the person wherever they pass out. This strategy is designed to help stop enabling behaviors. Also, CRAFT utilizes positive reinforcement but finding alternative behaviors or activities that do not involve alcohol or drug use and helping to promote those alternatives. In the $\mathrm{HBO}$ video series Addiction (Meyers, 2007), there is a segment on CRAFT in which a grandmother is coached on how to utilize CRAFT principles with her young adult grandson, Doug. In coming up with ways to reinforce Doug for nonusing behaviors, the grandmother mentions that Doug used to play the guitar and had expressed interest in playing the drums. The counselor and grandmother then discuss how to use these interests as positive reinforcement for the grandson.

Finally, the CRAFT approach is really about helping family members. Meyers provides a list of Five Things to Know About Coping With a Loved One's Unhealthy Behavior which are as follows:

1. Your love has power.

2. You are not alone.

3. You can catch more flies with honey than with vinegar.

4. You have as many tries as you want. Relationships are a process.

5. You can live a happier life whether or not your loved one sobers up (Meyers p. 159 in Hoffman \& Froemke, 2007a).

These coping statements are really about empowering family members and providing hope (family members can learn techniques that can help motivate their loved one to recovery) and that they are not alone in their struggles. The emphasis is also on helping family members try new approaches and techniques in order to break old ways of communicating that have become totally ineffective.

There are several advantages and disadvantages to CRAFT. The main advantage is that this approach is considered to be one of the least coercive approaches to help motivate family members or other loved ones to accept treatment. CRAFT also offers several ways to help loved ones communicate concerns about alcohol or drug use. CRAFT is also very advantageous in supporting loved ones and making them aware that they are not alone in their struggle. The main disadvantage is that this approach is not applicable to everyone. For example, in instances where there may be a more immediate danger of overdose or where an inpatient detox is usually the safest choice, there may not be enough time to teach the basics of the CRAFT approach. Although CRAFT is a sound evidenced-based approach when a loved one is actively abusing substances, this is not to say that CRAFT might not be useful in supporting the family once their loved one is in recovery because it really does help to eliminate dysfunctional communication patterns.

CRAFT is also helpful for partners/spouses as it allows them to focus on their own reactions to their loved one's drinking or drug use behavior (Meyers et al., 2001, 2002; Smith 
et al., 2004). By encouraging family members to alter negative communication/confrontations, by refraining from specific enabling behaviors, and by positively reinforcing nonsubstance use behaviors, CRAFT assists these spouses/partners to change how they respond to their loved one. Dittrich and Trapold (1984; Dittrich, 1993) developed a brief treatment package that they utilized with a sample of 52 women who were living with a SUD partner. Following this brief group counseling intervention, the women had significantly reduced enabling behaviors and also reported reduced levels of depression and anxiety. In yet another treatment program, Thomas et al. $(1994,1996)$ were able to identify enabling behavior of 68 spouse living with a SUD partner, and, through a combined approach of psychoeducation and counseling, there were reductions in enabling behaviors.

\section{Considerations Regarding Enabling}

Enabling is a particular type of behavior that reinforces drinking and drug use behavior. As defined by Doweiko (2009), enabling is "knowingly behaving in such a way as to make it possible for another person to continue to use chemicals, without having to pay the natural consequences for his or her substance use disorder" (p. 291). In addition, enabling is often based on a set of beliefs that one must tolerate, minimize substance use, or do whatever it takes to support their partner no matter how severe their drinking or drug use is. In some instances, enabling emanates from guilt or fear. Therefore, enabling can easily be viewed from both a behavioral as well as a cognitive-behavioral framework. From a behavioral perspective, specific enabling behaviors are examined while, from a cognitive-behavioral perspective, beliefs that underlie enabling behaviors are examined. A common enabling pattern among parents who have an adolescent or young adult who is active in their SUD and living in their home; is to provide that son or daughter with money or access to credit cards as a means to assuage the parent's guilt for some past transgression (e.g., infidelity, separation/ divorce, and past parental substance use). The absolute worst-case scenario is when parents condone substance use or will drink or smoke cannabis with them, rationalizing "what's the harm with having a beer or smoking a joint with my son/daughter. It's better than their shooting up heroin." Nothing positive comes from enabling, yet many parents get caught up in the illusion that enabling behaviors will somehow prevent a worse outcome (e.g., an overdose, injury, or arrest).

Family members often find themselves in a predicament of not knowing how to help their loved one who is struggling with a SUD. There is often a thin line between what is considered helping versus that which would be considered enabling. In addition, a few decades ago, it was common for counselors to conclude that enabling behaviors on the part of the non alcohol/substance spouse, partner, or parent was evidence of pathological personality traits (e.g., dependent personality disorder or traits) that caused them to engage in irrational enabling behaviors. More recently, however, the prevailing view is that enabling behaviors are normal reactions to the stress caused by a loved one who is experiencing a SUD (Asher \& Brissett, 1988; Haaken, 1990; Hands \& Dear, 1994; Miller, 1994). Yet, it is also important to keep in mind that not all families exhibit enabling behaviors and some are able to take on an opposite, "tough-love" type of approach. Rotunda and Doman (2001) have advocated that the terms codependency and enabling stop being used synonymously and that codependency is a pejorative label that should be totally eliminated. As Rotunda and Doman point out, 
"having a problem is not the same as being the problem, an implication of extending the disease model to codependent family members..." (p. 259). With this in mind, it is important to properly assess and treat enabling behaviors. With regard to assessment, Rotunda (1996) has developed the Behavioral Enabling Scale (BES). The BES is composed of two subscales: the enabling behaviors subscale and the enabling beliefs subscale (see Appendix 8.2). The enabling behaviors subscale consists of 20 items to which participants respond on a 5-point Likert scale (ranging from 1 = not at all, $2=$ rarely, $3=$ sometimes, $4=$ often, and $5=$ very often) and contains items related to a variety of enabling behaviors such as giving the partner money to buy alcohol or drugs, making excuses for partner when they were too impaired to execute obligations, and helping the partner by nursing their hangover. The enabling beliefs scale consists of 13 items to which participants respond on a 4-point Likert scale ranging from -2 strongly disagree to +2 strongly agree. The enabling beliefs subscale contains items pertaining to one's beliefs regarding enabling, such as it being the nonaddicted partner's responsibility to change their loved one's drinking or drug use or the nonaddicted partner feeling and their responsibility to hold the relationship together, or the belief that their partner cannot get along without their help. Although score interpretation is unspecified, it is assumed that scores on the enabling behaviors subscale that fall between 80 and 100 are indicative of extreme enabling behaviors and scores on the enabling beliefs subscale that fall between 39 and 52 are indicative of extreme endorsement of enabling beliefs. In a validation study of the BES, Rotunda et al. (2004) found that a higher incidence of enabling beliefs correlated with increased rates of enabling behaviors.

As mentioned earlier, whenever possible it is important that non-SUD family members participate in AA and/or NA in addition to whatever counseling they receive. Be aware that there are some AA and NA meetings that are directed more to spouses and partners, while there are other meetings that are directed more to parents and grandparents. In either instance, the message tends to be similar, that is, "detach with love." See Box 8.4. It is no coincidence that the First Step of AA/NA and AA and NA are the same, that is, "We admitted we are powerless over alcohol/drugs, and our lives had become unmanageable." Enabling behaviors are the exact opposite of "admitting we are powerless" as families/spouses/partners often labor under the false belief that their enabling behavior will somehow protect their loved one and keep them safe. Instead, AA and NA promote that families adopt the 3 Cs: "I didn't Cause it, I can't Control it, I can't Change it." By adopting the 3 Cs, one is essentially admitted they are powerless to change and control their loved one's SUD.

\section{Kasl's 16 Step Approach to Codependency}

Dr. Charlotte Kasl (2020) has developed a rather unique approach to treating and managing codependency. Instead of viewing codependency from the lens of addiction (i.e., a loved one being addicted to helping someone with a SUD or some other dysfunctional behavior), Kasl put forth a viewpoint that perceives codependency as a form of internalized oppression that can best be viewed within a cultural perspective that takes into account sexism, racism, classism, and homophobia. The 16 Steps that Kasl developed are holistic and fluid in that it evolves as the client is evolving, growing, and changing In some respects, the 16 Steps are based on the 12 Steps of AA, however, they are empowerment-minded and go beyond the traditional 12 Steps. For example, Step 4 of the traditional 12 Steps asks individuals to take 


\section{BOX 8.4}

\section{DETACHING WITH LOVE}

Detaching from a loved one's substance use disorder (SUD) is often easier said than done. Family members, spouses, and partners often struggle to let go of their loved one's substance use laboring under the belief that they can somehow control their use or prevent them from relapsing or that their loved one is incapable of recovering without their hypervigilance and scrutiny. Yet, detachment may appear to someone not familiar with SUD recovery to be selfish or uncaring. Nothing can be further from the truth, as put forth by Beverly Conyers (2015) who has developed a list of recommendations of reasons and ways that nonaddicted family members and significant others can detach. First, Conyers feels that detachment allows "fresh air" into the relationship or an opportunity to let go of unhealthy patterns of interaction such as nagging, crying, scolding, or threatening. Second, detachment allows the addicted loved one to face consequences of their substance use which provides opportunities for learning from these experiences. Often family members or significant others are the one's who suffer the consequences (e.g., when a loved one pays a DUI fine or household bills). Third, detachment helps to save the addicted loved one from the potentially harmful effects of enabling by having the opportunity to face problems themselves. Fourth, detachment empowers the addicted love to take on adult responsibilities, for example, to become financially self-supporting which also allows them to experience the satisfaction of "living life on life's terms" and behaving like a mature adult. Fifth, detachment reduces the shame that the addicted love one often feels for having ruined their lives and from continually disappointing others. Finally, true detachment is truly an expression of unconditional love. It is similar to saying to the loved one, "I believe you have the intelligence, determination and inner strength to recover...you can handle this yourself."

Source: Adapted from Conyers, B. (2015, September 15). Detaching with love: Eight reasons why detaching is good for your addicted love one. Hazelden Betty Ford Center.

a "fearless moral inventory," whereas Kasl's Fourth Step suggests, "We examine our beliefs, addictions and dependent behavior in the context of living in a hierarchical, patriarchal culture." Similarly, Kasl's Eighth Step recommends, "We make a list of people we have harmed and people who have harmed us, and take steps to clear out negative energy by making amends and sharing our grievances in a respectful way."

The advantage of Kasl's approach is that it takes a cultural diversity perspective into account when working with clients, rather than pathologizing or judging their behavior as abnormal or aberrant (Kasl, 2020). Therefore, this model seeks to empower clients as they evolve and change codependent behaviors.

\section{Assessing Families}

When assessing families, it is important not only to get a thorough history of the family's presenting complaint but also to obtain history of the family or couple and some of the difficulties or adversities they may have faced. In the example of Brittany, the death of her older brother plays a central role in the dynamics of this family. Similarly, consider a father of a 
teenage son who is smoking cannabis and drinking on weekends who takes a very protective and strict approach toward his son's substance use because the father's brother had died of a drug overdose two years ago. In this instance, family history is very important to gaining a more complete picture of the father's reaction to his son's substance use. Often when addiction counselors are seeing families for the first time, they are seeing them at their lowest or most desperate point. Therefore, it is helpful for counselors to also get a sense of the family's strengths, things they are most proud of, and their hopes for the future. Counselors must also take race, ethnicity, religious, social class, and cultural influences into account, as these factors will certainly shape family values, beliefs, and attitudes. In order for counselors to have an appreciation of the influences of race, ethnicity culture, we highly recommend that you read Ethnicity and Family Therapy by McGoldrick et al. (2014) which contains chapters on treating Native Americans, African Americans, Immigrant African families, indigenous Hawaiian families, Latino Americans, Jewish families (including Israeli, Orthodox, and Russian Jewish families), and a variety of European American and Slavic American families. A criticism of examining ethnic-racial-cultural uniqueness is that there may be a danger of stereotyping families. For example, if we were to say that all Latinx families held the same religious or familial values, we would be missing the important nuances between Mexican American, Cuban American, and Puerto Rican families who may be similar in terms of a common language but are different when it comes to culture.

You are probably familiar with the popular expression, "A picture's worth a thousand words." This familiar phrase is very much applicable to the use of genograms as an assessment tool that can be used with families. Family genograms (McGoldrick et al., 2020) are helpful in examining interactional and behavioral patterns within the family milieu. For example, by gathering information about how the family interacts, we may see enabling patterns and other types of dysfunctional behavior. We may see examples of who colludes or allies with whom, or whether there may be enmeshed relationships between a father and teenage daughter or a mother and teenage son. Enmeshed relationships are also ripe for triangulation as "third parties" get unwittingly drawn into conflicts between parents and their teenage sons or daughters. The genogram can also tell us about family roles as we begin to hear which children have taken on roles of hero, scapegoat, clown-mascot, or lost child. Appendix 8.3 provides an example of a four-generation genogram in which the oldest son is the IP and he is experiencing a cocaine use disorder (noted by double lines). Although neither parents of this oldest son are experiencing any substance

\section{LEARNING ACTIVITY 8.5 HELPING VERSUS ENABLING}

Imagine a family that has a son or daughter is actively using alcohol and drugs, then develop a list of behaviors that would be examples of helping and a list of behaviors that would be examples of enabling. Also, consider the following scenario: Gina is 25 years old and has just completed a residential treatment program for her Benzodiazepine and alcohol use disorders. She is now back living at home with her parents. Gina was fired from her last job because she was constantly calling in sick (because she was too hung over). Gina's aftercare plan indicates hat she will attend AA and NA meetings and attend an IOP. Unfortunately, Gina had totaled her car (while DUI), so she does not have transportation. She is pressuring her parents to buy her a car so she can get to meetings and IOP. Her mother feels this is a reasonable request for help, however, her father feels this enabling. What are your opinions? Discuss with your classmates. 
use issues, it is noted that there is a paternal aunt who is depicted as having an alcohol use disorder and an uncle (on the mother's sides of the family) who is experiencing an opioid use disorder. The format and symbols that are used to compose a genogram are also included at the bottom of Appendix 8.3.

\section{ADOLESCENT FAMILY TREATMENT}

\section{Adolescent Family Treatment Models}

Adolescents who develop SUDs are especially problematic, and therefore, require specialized treatment. Just as there are various types of inpatient or residential SUD treatment programs for adults, so too there are residential treatment programs specifically for adolescents. Adolescent treatment programs, in general, tend to be more highly structured and activity oriented. In addition, it is imperative that adolescent treatment programs contain a strong family counseling component because without the help and support of the teenager's family, relapse becomes more likely. Through treatment, families can make changes toward becoming part of the solution rather than being part of the problem. The following are a few examples of adolescent family treatment models:

\section{Multisystemic or Multidimensional Family Therapy}

This approach is primarily a family-based outpatient, SUD model that requires close collaboration between the adolescent, their family as well as contacts with the adolescent's school and juvenile justice system (if they are mandated to treatment by the courts). The family counselor is responsible for meeting with the adolescent, with the adolescent and their family members, and also with school counselors and juvenile justice officers on an ongoing basis. The goal of these sessions is to provide structure to the adolescent's life by helping to reinforce the family, school, and community's rules and expectations. The other goal is to help prevent the adolescent's SUD from progressing or escalating to a point where residential treatment would become necessary. The HBO video series Addiction (Hoffman \& Froemke, 2007b) provides a good video illustration of the Multisystemic Family Therapy approach.

\section{Functional Family Therapy}

The Functional Family Therapy (FFT) approach was created by therapists Alexander and Parsons (1982) who at the time were working with youth who exhibited a variety of conduct disorders. FFT utilizes a combination of behavioral techniques along with a family systems perspective. From the very onset, FFT family therapists work with both the adolescent and their parents and siblings with the goal of examining how their day-to-day interactions function to regulate their relationships. The behavioral aspect of FFT explores the "payoffs" or reinforcers that maintain or reinforce certain maladaptive behaviors between family members (Waldron \& Turner, 2008; Waldron et al., 2001). Alexander and Parsons (1982) describe three behavioral patterns of interaction that are often experienced by families impacted by an adolescent son or daughter's substance use. They are (1) merging, which is meant to increase closeness and contact (e.g., even in arguing with one another, family members are engaged or connected to one 
another); (2) separating, which is meant to create distance and autonomy (e.g., an adolescent may have very little interaction with their parents in order to obtain more independence); and (3) midpointing, which involves a combination of both merging and separating behaviors (e.g., the adolescent may at one time say, "Pay attention to me, listen to me," while at other times may be saying, "Go away, leave me alone"). According to the FFT model, it is the very nature of these interpersonal family relationships that create problems within the family. The challenge of the FFT approach is to encourage family members to gain a new perspective in which they can look at their own roles in maintaining certain dysfunctional behaviors.

Most of the research on FFT has focused on its impact on acting out or externalizing behaviors (i.e., criminal behaviors); for example, Sexton and Turner (2011) found significant reductions in felony and violent crimes. One study focused specifically on utilized FFT with substance use (Waldron et al., 2001) and found significant reductions in adolescent marijuana use as a result of FFT therapy. Furthermore, the greatest reductions in marijuana use occurred in the families that participated in a combination of both FFT and cognitive behavioral therapy.

\section{NOTES FROM THE FIELD}

\section{Carolann Kane, MA, LCADC}

Carolann Kane is the Executive Director of the Samaritan Center in Manasquan, NJ, an outpatient mental health and SUD counseling program. The Samaritan Center counselors treat both individuals with SUDs as well as family members who sometimes will seek help because of concerns for their loved one's substance use. The Samaritan Center is designed to provide counseling to family members at various entry points and utilizes supportive counseling and 12-Step Facilitated Counseling (encouraging AA and NA involvement) and other counseling approaches described in this chapter. According to Carolann, the main challenge is helping the family member to detach from their loved one's behavior and to develop strategies that help stop enabling behavior by allowing the substance users to experience natural consequences of their alcohol and/or substance use. Many family members seek counseling feeling guilty and responsible for their loved one's SUD, therefore, it is important that counselors work with them on letting go of these feelings that might prevent them from taking productive steps.

\section{SUMMARY}

SUDs do not occur in a vacuum. Not only does the SUD person suffer but so do their families and significant others. Families can often become part of the solution or part of the problem when it comes to SUDs, therefore, it is imperative that families and significant others be involved both in motivating loved ones to enter treatment, also while they are in treatment and then when they return home. This chapter reviews some of the major theoretical models that conceptualize how SUDs impact on family members and how these models can be utilized to help bring about change. In addition to presenting basic conceptualization of Family Systems, Structural Family Theory, the Family Disease Model, and Behavioral/Cognitive Behavioral Theory, we also presented information on the CRAFT approach and Kasl's approach for treating codependency as well as adolescent family treatment approaches. 


\section{RESOURCES}

Anderson, C. M., \& Stewart, S. (1983). Mastering resistance: A practical guide to family therapy. Guilford Publications.

Bekir, P., McLellan, T., Childress, A. R., \& Gariti, P. (1993). Role reversals in families of substance misusers: A transgenerational phenomenon. International Journal of Addictions, 28(7), 613-630. https://doi.org/10.3109/10826089309039652

Brown, S., \& Lewis, V. (1999). The alcoholic family in recovery: A developmental model. Guilford Press.

Families and Addictions (Website): This website was developed by the Substance Abuse and Mental Health Services Administration (SAMHSA) and lists a number of publications. https://www.samhsa .gov/find-help/national-helpline

Family Behavior Therapy (Website): This guide to behavioral family therapy is presented by the National Institute of Health's (NIH) National Institute on Drug Abuse (NIDA) https://www.drugabuse.gov/ publications/principles-drug-addiction-treatment-research-based-guide-third-edition/evidence -based-approaches-to-drug-addiction-treatment/behavioral-5

Family Genogram Programs (Websites): These websites provide programs for writing creating genograms. Some sites provide free samples, others charge usage fees. www.genogramanalytics.com/index.html

How to Make a Genogram (Website): This is from WikiHow.com and provides a step-by-step model for creating a genogram. https://www.wikihow.com/Make-a-Genogram

Introduction to the Genogram: https://www.genopro.com/genogram/

Jackson, J. K. (1954). The adjustment of the family to the crisis of alcoholism. Quarterly Journal of Studies on Alcohol, 15(4), 562-586.

Johnson, V. (1973). I'll quit tomorrow. Harper \& Row.

McCrady, B. S., Owens, M. D., \& Brovko, J. M. (2013). Couples and family treatment methods. In B. S. McCrady \& E. E. Epstein (Eds.), Addictions: A comprehensive guidebook (2nd ed., pp. 454-481). Oxford University Press.

McGoldrick, M., Giordano, J., \& Garcia-Preto, N. (2014). Ethnicity and family therapy (3rd ed.). Guilford Publications.

Stanton, M. D., \& Todd, T. C. (1982). The family therapy of drug abuse and addiction. Guilford Press.

Steinglass, P., Bennett, L. A., Wolin, S. J., \& Reiss, D. (1987). The alcoholic family. Basic Books.

Substance Abuse Treatment and Family Therapy (Website): This one of SAMHSA's Treatment Improvement Protocols which provides in depth information on family therapy. https://www.ncbi.nlm.nih.gov/ books/NBK64269/

What is a genogram? (You Tube video): This brief video describes what a genogram is and how it can be used in counseling. https://www.youtube.com/watch?v=MuXvG9tbUMs

Wegsheider, S. (1981). Another chance: Hope and health for the alcoholic family. Science \& Behavior Books. Woititz, J. G. (1983). Adult children of alcoholics. Health Communications Inc.

\section{KEY REFERENCES}

Only key references appear in the print edition. The full reference list appears in the digital product on Springer Publishing Connect: connect.springerpub.com/content/book/978-0-8261-3586-5/chapter/ch08

Ackerman, R. (1981). Perfect daughters: Adult daughters of alcoholics. Health Communications.

Anderson, C. M., \& Stewart, S. (1983). Mastering resistance: A practical guide to family therapy. Guilford Publications.

Brown, S., \& Lewis, V. (1999). The alcoholic family in recovery: A developmental model. Guilford Press.

Cavaiola, A. (2000). In search of a new metaphor for the impact of drug abuse on families. Family Therapy, 27(2), 81-87. https://doi.org/10/1080/08897077.2015.1029207

Halpern, S. C., Schuch, F. B., Scherer, J. N., Sordi, A. O., Pachado, M., Dalbosco, C., Fara, L, Pechansky, F., Kessler, F., \& Von Diemen, L. (2018). Child maltreatment and illicit substance abuse: A systematic review and meta-analysis of longitudinal studies. Child Abuse Review, 27, 344-360. https://doi .org/10.1002/car.2534

McGoldrick, M., Giordano, J., \& Garcia-Preto, N. (2014). Ethnicity and family therapy (3rd ed.). Guilford Publications. 
Meyers, R. J., Miller, W. R., \& Smith, J. E. (2001). Community reinforcement and family training (CRAFT). In R. J. Meyers \& W. R. Miller (Eds.), A community reinforcement approach to addiction treatment (pp. 147-160). Cambridge University Press.

O’Farrell, T. J., Murphy, C. M., Stephan, S. H., Fals-Stewart, W., \& Murphy, M. (2004). Partner violence before and after couples-based alcoholism treatment for male alcoholic patients: The role of treatment involvement and abstinence. Journal of Consulting and Clinical Psychology, 72(2), 202-217. https://doi .org/10.1037/0022-006X.72.2.202

Rotunda, R. J., West, L., \& O'Farrell, T. J. (2004). Enabling behavior in a clinical sample of alcoholdependent clients and their partners. Journal of Substance Abuse Treatment, 26(4), 269-276. https://doi .org/10.1016/j.jsat.2004.01.007

Stanton, M. D., \& Todd, T. C. (1982). The family therapy of drug abuse and addiction. Guilford Press.

Stanton, M. D., Todd, T. C., Heard, D. B., Kirshner, S., Kleiman, J. I., Mowatt, D. T., \& Vandeusen, J. M. (1978). Heroin addiction as a family phenomena: A new conceptual model. American Journal of Drug and Alcohol Abuse, 5(2), 125-150. https://doi.org/10.3109/00952997809027993

Steinglass, P., Bennett, L. A., Wolin, S. J., \& Reiss, D. (1987). The alcoholic family. Basic Books.

Tseng, K. C., Hemenway, D., Kawachi, I., \& Subramanian, S. V. (2010). Family ties and the frequency of heroin use. Journal of Substance Use, 15(1), 60-74. https://doi.org/10.3109/14659890903010501

Wolin, S. J., Bennett, L. A., Noonan, D. L., \& Teitelbaum, M. A. (1980). Disrupted family rituals: A factor in the intergenerational transmission of alcoholism. Journal of Studies on Alcohol, 41(1), 199-214. https://doi.org/10.15288/jsa.1980.41.199 


\section{APPENDIX 8.1}

\section{FAMILY TREATMENT AGENDA (FOR INPATIENT OR INTENSIVE OUTPATIENT PROGRAM)}

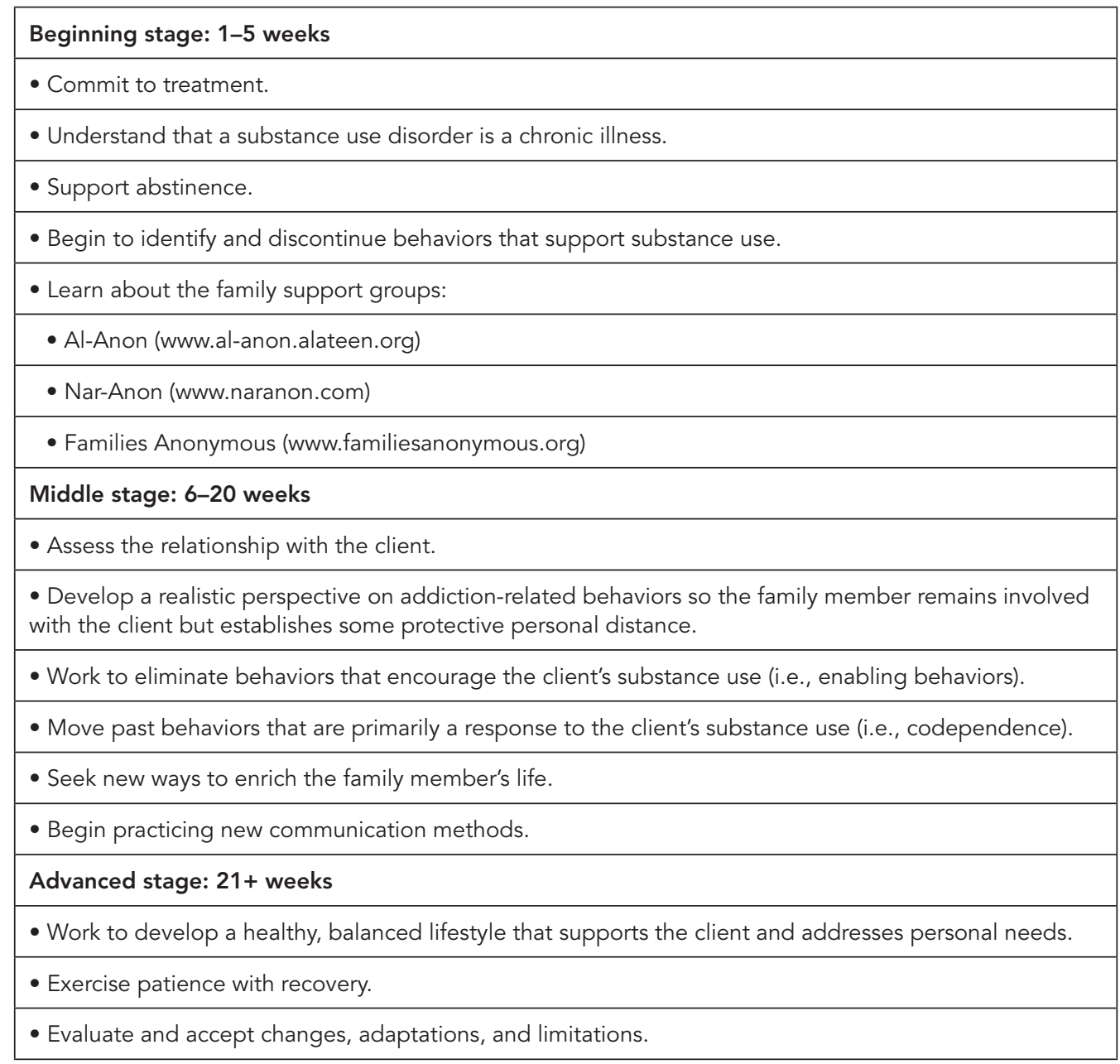

Source: Derived in part from the Matrix Center. (1989). The matrix model of outpatient chemical dependency treatment: Family education guidelines and handouts. The Matrix Center. 


\section{APPENDIX 8.2}

BEHAVIORAL ENABLING SCALE (ROTUNDA ET AL., 2004)

\begin{tabular}{|l|l|l|l|l|}
\hline 1 & 2 & 3 & 4 & 5 \\
\hline Not at all & Rarely & Sometimes & Often & Very Often \\
\hline
\end{tabular}

\section{Enabling Behaviors}

1. Partner gave money to client to buy alcohol/drugs.

2. Partner purchased alcohol or drugs for client.

3. Partner taken over client's neglected chores because they were drinking/drugging.

4. Partner lied or made excuses to family/friends to hide client's drinking/drugging.

5. Partner drank/used drugs with client or in client's presence.

6. Partner told client it was okay to drink or use drugs on certain days or for special family or social gatherings.

7. Partner borrowed money to pay bills caused by client's drinking/drug use.

8. Partner changed or cancelled family plans or social activities because client was drinking, using drugs, or hung over.

9. Partner had sex with client when really did not want to because they had been drinking or drugging.

10. Partner asked for help from the police, a judge or lawyer, or other professional to get client out of trouble related to drinking or drug use.

11. Partner threatened client with separation because of the drinking or drug use but but later did not follow through with it.

12. Partner paid lawyer or court fees, or bailed client of jail due to drinking or drug-related offense.

13. Partner helped nurse client through a hangover.

14. Partner cleaned up (vomit, urine, etc.) after client got sick.

15. Partner asked or encouraged family members to ignore or be silent about client's drinking or drug use.

16. Partner helped conceal client's drinking or drug use from employers or co-workers.

17. Partner coaxed client up in the morning to go to work when they were hung over.

18. Partner made excuses to others for client's impaired behavior when they were drinking or high.

19. Partner reassured client that his/her drinking or drug use was not that bad.

20. Partner lied or told half-truth to a physician, counselor, probation officer, judge, and police officer about client's alcohol or drug use, or participation in treatment programs. 


\begin{tabular}{|l|l|l|l|}
\hline 1 & 2 & 3 & 4 \\
\hline Strongly Disagree & Disagree & Agree & Strongly Agree \\
\hline
\end{tabular}

\section{Enabling Beliefs}

1. It is my duty to take on more responsibility for home and family obligations than my partner in times of stress.

2. I often feel I should take care of my partner regardless of what they do.

3. I can change my partner's drinking or drug use habits and make them stop if I want.

4. I am one of the main reasons my partner has alcohol or drug abuse problems.

5. It is okay that my partner drinks or uses drugs as long as they control how much they use.

6. Sometimes I like when my partner is drinking or high because they are more affectionate and more able to express positive feelings.

7. I miss certain aspects of our daily lifestyle when my partner stops drinking or using drugs (e.g., socializing, entertaining).

8. I need to do whatever it takes to hold my relationship with my partner together.

9. I often do not do or say anything bout my partner's alcohol or drug use because it might make it worse or cause more conflict/tension.

10. I often ignore, deny, or minimize the seriousness of my partner's alcohol or drug use.

11. I tolerate my partner's drinking or drug use as long as they keep working and earning money.

12. I should do my best to protect my partner from the negative consequences of his/her alcohol or drug use.

13. My partner cannot get along without my help.

Source: Adapted from Rotunda, R. J., West, L., \& 0'Farrell, T. J. (2004). Enabling behavior in a clinical sample of alcohol-dependent clients and their partners. Journal of Substance Abuse Treatment, 26, 269-276. Reproduced with permission of Elsevier. 


\section{APPENDIX 8.3}

\section{FAMILY GENOGRAM}

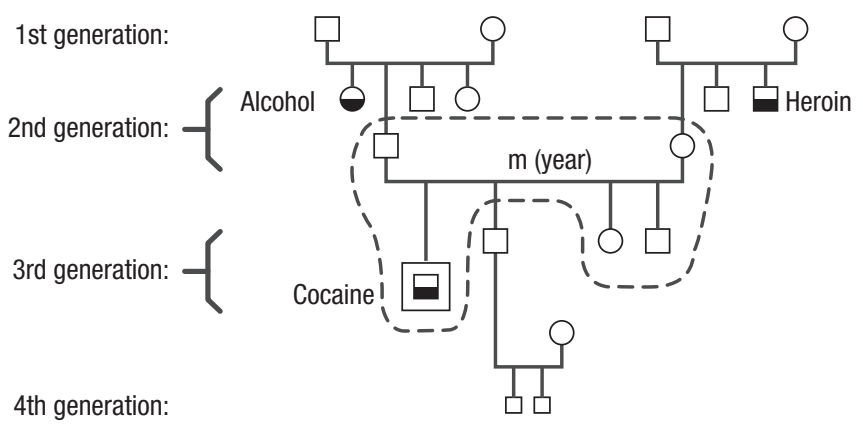

Symbols useful for genograms

\section{Symbols}

$\square=$ Male

$\mathrm{O}=$ Female

$\square$ (O) = Client

$\square=$ Alcohol or drug abuse (indicate drug of abuse)

D $=$ Mental or physical illness

- Alcohol or drug abuse and mental or physical problems

$\mathrm{X} \otimes=$ Deceased

Members of client's household (dotted lines):

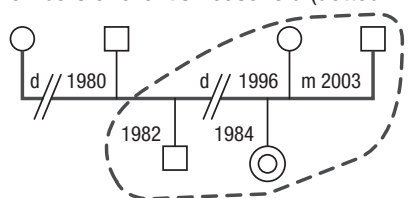

\section{Relationships}

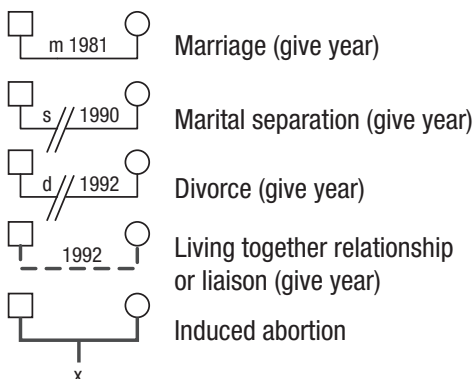

Children: List in birth order with birth year Adopted or foster children $=$ dotted line Note any changes in custody

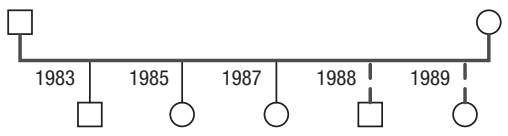

\section{Family interaction patterns (nature of relationship)}

$\square \longrightarrow$ Distant

$\square \equiv \bigcirc$ Very close

$\begin{array}{ll}\square \longmapsto & \text { Estranged/cut off } \\ \square \sim O & \text { Conflictual }\end{array}$

$\square O$ Fused and conflictual (a bond of ongoing conflict that is mutually satisfying and/or rewarding) 
